\title{
REDIMENSIONAMENTO DA UTILIZAÇÃO DOS ESPAÇOS PÚBLICOS NAS CIDADES
}

Recebido em: 26/12/2017

Aceito em: 22/09/2018

Rosalvo Luis Sawitzki ${ }^{1}$

Universidade Federal de Santa Maria (UFSM)

Santa Maria - RS - Brasil

RESUMO: Este artigo tem por objetivo refletir sobre a estruturação e/ou reorganização de espaços públicos como locais de formação permanente, de prestação de serviços públicos, de convivência social, cultural, esportiva e de lazer. Nesse contexto, entendese como significativo o planejamento participativo, a organização e a realização nas cidades de programas sociais, culturais, educativos, esportivos e de lazer como alternativa para contribuir com a humanização da sociedade, convívio comunitário, melhoria da qualidade de vida e desenvolvimento social, em ambientes saudáveis, sustentáveis e de acesso público.

PALAVRAS CHAVE: Espaços Públicos. Formação Permanente. Convívio Comunitário.

\section{REDIMENSIONING THE USE OF PUBLIC SPACES IN CITIES}

ABSTRACT: This article aims to reflect about the structuring or reorganization of public spaces as places of lifelong learning, to provide public services, social and cultural harmony, sporting and leisure activities. In this context, it is understood as meaningful the participatory planning, the organization and execution in the city which have social programs, cultural, educative, sportive and of leisure as an alternative to contribute with the humanization of the society, of community living, of life improvement and social development, in a healthy, sustainable and of public access environment.

KEYWORDS: Public Spaces. Permanent Formation. Community Living.

\footnotetext{
1 Professor do Departamento de Esportes Individuais do Centro de Educação Física e Desportos - CEFD da Universidade Federal de Santa Maria (UFSM).
} 


\section{Primeiras Considerações}

Os espaços públicos existentes nas cidades, em geral, demonstram visivelmente os conflitos estruturais urbanos na sociedade contemporânea. Hoje, de modo geral, quem não pode pagar por esses espaços está condenado a ficar excluído desses espaços. O acesso a espaços, tais como a escola pública e seu pátio no turno não escolar, o campo de futebol, o ginásio, o parque, a praça, a piscina, o lago, a mata, o rio, que deveria ser possibilitado a todos os cidadãos, como um direito seu, não está sendo garantido de forma igualitária, mas sim para aqueles que podem pagar para poder usufruí-los.

Outra realidade é a de que, muitas vezes, as políticas públicas sociais de governo, destinadas às comunidades, não problematizam essa falta de acessibilidade à comunidade para com esses espaços. Também, em muitos locais e/ou materiais relacionados à convivência comunitária, convive-se com a falta de segurança, higiene, com equipamentos sucateados, e, em muitos casos, apresentam-se como uma ameaça à integridade física das pessoas, pelo seu estado de deterioração e abandono.

A recorrente falta de preservação dos espaços públicos e dos equipamentos por parte dos gestores públicos é fator determinante para o afastamento da comunidade da sua utilização, especialmente por crianças e jovens. Nesse sentido, o que se percebe é a retirada do Estado, enquanto responsável por garantir à sociedade essas políticas sociais, contribuindo de forma significativa para a entrada da indústria do entretenimento, por meio da iniciativa privada, a qual passa a organizar eventos pagos. Além disso, temos, amiúde, a presença do mercado imobiliário, que está a absorver espaços públicos que permitiam à comunidade em geral momentos de educação, reunião, convivência, discussão de problemas, prática de atividade esportiva e de lazer. 
A estruturação e/ou reorganização de espaços públicos como locais de educação da sociedade como um todo, de prestação de serviços públicos, de convivência social, cultural, esportiva e de lazer, apresenta-se como uma possibilidade de suprir algumas demandas por esses serviços. Nesse contexto, entende-se como significativo o planejamento participativo e a realização de programas sociais, culturais, artísticos, educativos, esportivos e de lazer em ambientes confortáveis, sustentáveis e de acesso público, como mais uma alternativa para contribuir com a humanização da sociedade, de convívio comunitário, de melhoria da qualidade de vida e de desenvolvimento social.

Salientamos, mais uma vez, a possibilidade educacional desses espaços e de forma positiva para proporcionar uma vida melhor a todos os que possam usufruir desses locais, já que, a educação também se define por fatores sociais mais amplos que não apenas escola e família (DIETRICH; LANDAU, 1990). Assim, define-se a educação pela totalidade das relações sociais que impactam na vida da criança e do jovem. A educação é, dessa forma, a somatória de reações oriundas dos contextos socioculturais que influenciam a totalidade dos fatores de desenvolvimento do ser humano, em especial crianças e jovens. Nessa perspectiva, necessitamos de um melhor aproveitamento, incluindo a ampliação dos espaços públicos aqui referidos, tendo em vista as excelentes oportunidades educacionais; e que esses espaços possam realmente promover uma educação desejável e favorável à vida de crianças e jovens, e não o contrário, como muitas vezes pode ser visto, ou seja, espaços que poderiam muito bem servir para práticas de esporte, sendo ocupado para consumo de droga e outras ilegalidades e prejudiciais á vida do jovem.

Para que uma cidade seja considerada com qualidade de vida, acredita-se que tudo o que for planejado e executado ocorra a partir da prioridade maior: seus 
indivíduos. Percebe-se que uma das políticas de governo a ser desenvolvida - a educação geral das pessoas, na perspectiva de que se desenvolvam de forma contínua e ao longo de toda a vida, em todos os seus espaços de atuação - não pode se restringir à educação escolarizada ou meramente profissional.

No livro organizado por Moll (2012), Caminhos da Educação Integral no Brasil: direito a outros tempos e espaços educativos, há referências a diferentes autores, como Anísio Teixeira, Darci Ribeiro e Paulo Freire, em relação as suas preocupações sobre Educação Integral e os seus pressupostos conceituais e históricos sobre a necessidade de se buscar uma educação "(re)humanizadora", no sentido de desenvolver problematizações sobre qualidade social da educação pública. Um dos pontos centrais dessas preocupações seria, conforme Arroyo (2012), a superação da precarização dos espaços e dos tempos do viver. Ou seja: desenvolver possibilidades para que aconteçam vivências dignas nos diferentes espaços privados (moradias) e públicos (ruas, parques, praças etc.), a fim de permitir o desenvolvimento de um tempo social da infância, da adolescência e da fase adulta.

Essas preocupações de Arroyo podem ser alinhadas a um movimento internacional das chamadas Cidades Educadoras, que tem início em 1991 com um Congresso Internacional sobre o tema na cidade de Barcelona (Espanha). Foi nesse congresso que diferentes cidades desenvolveram alguns princípios que pudessem orientar as administrações públicas a uma preocupação com os espaços públicos em sentido educativo. Dessa forma, surge a Carta das Cidades Educadoras, que foi elaborada e aprovada no III Congresso Internacional, em Bolonha, na Itália, em 1994. Essa carta continua a ser uma referência importante para as mais de 400 cidades, em 
mais de 40 países em torno do mundo, que fazem parte da Associação Internacional de Cidades Educadoras; há, inclusive, algumas poucas cidades brasileiras nesta associação.

Quando aprendemos através da cidade e, na cidade, colocamos em jogo duas questões, ou seja, conhecer a cidade e, simultaneamente, usar suas diferentes possibilidades, evidenciou a necessidade da aposta na construção de referenciais para o desenvolvimento de uma forma de educação por meio da e na cidade e seus diferentes tempos e espaços públicos.

Assim, o chamado sistema não formal da educação adquire uma grande importância e que se relaciona com o sistema formal, determinando novos espaços e tempos para a criação de novos cenários educacionais. Nesse contexto é importante ver a questão da educação permeada pelos espaços e tempos culturais da cidade, desenvolvendo, inclusive, uma perspectiva de uma educação ecológica.

Segundo Ferreira (2007), a estruturação dos espaços públicos de convivência social, cultural, educativa, de esporte e de lazer tem como objetivo a organização de espaços de aprendizagens e de vivências/convivências, mediante a qualificação das estruturas físicas existentes, a democratização do acesso, a disponibilização de condições facilitadoras e iniciativas provenientes de várias áreas do saber, da cultura, do esporte, das artes, da economia e da ciência, considerando-as como um investimento cultural sistemático que, à luz de uma formação permanente, possibilite elevar o nível cultural, profissional e social da população que partilha do espaço urbano.

Uma das justificativas para a estruturação dos referidos espaços é a de que a sociedade está em contínuo processo de transformação, uma vez que as informações, o conhecimento e as inovações tecnológicas, cada vez mais, fazem parte do dia a dia das pessoas, influenciando na forma de pensar e viver, nas suas relações sociais, familiares, 
de produção e de consumo, no mundo do trabalho e na forma de se divertir, sentir prazer e de ser felizes.

\section{Os Espaços Públicos como Tempo-Lugar de Desenvolvimento Social}

As cidades, no contexto da sociedade contemporânea, estão deixando de ser um local prazeroso de se viver, onde as pessoas se encontram, trabalham, entrelaçam culturas e se divertem, para tornarem-se espaços com predomínio do individualismo, da exclusão social, da violência, do desemprego, da solidão e da fragmentação territorial/classial (vilas, favelas, condomínios, centros urbanos). Isto é, estão se tornando um ambiente antissocial, hostil e pouco favorável ao desenvolvimento humano e ao exercício da cidadania.

Nesse sentido, são necessárias alternativas de infraestrutura e políticas públicas para as cidades, visando resgatar a sua função social e contribuir com a humanização da sociedade e, também, com a estruturação de espaços onde se possa conviver com liberdade, amizade, paz, autonomia, responsabilidade e solidariedade entre as pessoas.

Pensar a cidade do futuro ou uma cidade humanizada não significa pensar a construção de uma nova cidade, mas, a partir da cidade em que habitamos, com sua estrutura física existente e com seus espaços sociais, rever as possibilidades de reorganizá-los, democratizá-los e qualificá-los para que possam contribuir com a qualidade de vida dos indivíduos em ambientes saudáveis e sustentáveis. Sendo assim, é importante criar ou redimensionar estruturas físicas, de recursos materiais/financeiros/humanos, de tal forma que a utilização de cada espaço seja, da melhor forma possível, voltada para o bem-estar social, pois é possível integrar espaços, estruturas, equipamentos e materiais, com vistas a constituir espaços públicos 
multifuncionais para a prestação de serviços públicos e a formação/qualificação das pessoas.

$\mathrm{Na}$ grande maioria das cidades, em seus diferentes espaços públicos, muito pouco de vida coletiva e participação comunitária se evidencia. A busca da humanização das estruturas existentes em nossas cidades é desafio que se propõe, visando torná-las locais de encontro, de humanização e de civilização, de forma que as pessoas possam viver e conviver em comunidade, discutir seus problemas e participar da vida social e política, no intuito de exercer os direitos sociais de cidadãos. "Na antiguidade, a cidade era a polis, a civitas, lugar supremo onde se dava a participação, a vida coletiva, a civilização e a cultura" (GOMEZ; VILA, 2001 p.13).

Poder viver no mundo contemporâneo está a exigir das pessoas, dos dirigentes políticos, do poder público, das empresas, das instituições sociais, das entidades representativas, dos sindicatos, dos partidos políticos, das universidades e das escolas uma mudança de postura e de responsabilidade social na busca da construção de um mundo mais humano e justo para todos. Para que isso aconteça, é necessária a presença efetiva do Estado, juntamente com a comunidade na participação dos processos decisórios, pois, do contrário, se reproduzirá o que historicamente tem acontecido nos diferentes projetos de diferentes governos: alguns pensam projetos para toda uma sociedade, e, em geral, esse pensar e executar estão muito distanciados da realidade e dos problemas cotidianos das pessoas.

Entende-se que a opção pela vida e sustentabilidade ambiental (seja no habitat local, seja no contexto global) é responsabilidade coletiva, pois são decisões que afetam a vida de toda a sociedade na sua forma de viver e conviver. Por isso, todos devem ser chamados e desafiados a ser partícipes nas tomadas de decisões. Necessitamos 
reivindicar novas formas de relações entre o poder político e a sociedade na organização das diferentes políticas públicas sociais.

Nessa mesma lógica, Bonalume (2005, p.34) defende que os pressupostos das referidas políticas públicas sociais a serem efetivadas por parte do Estado devem obedecer alguns princípios, sendo: Socialmente justas; e, Institucionalmente democráticas e participativas.

Entende-se que as cidades têm que ser planejadas levando em consideração a descentralização do poder e das decisões, no sentido de melhorar as ações e relações entre o Estado e a sociedade, por meio de políticas sociais de participação e corresponsabilidade. Considera-se importante buscar a melhoria da qualidade de vida das pessoas, bem como a inclusão e integração social daqueles que foram excluídos pelo sistema econômico, educacional, cultural, territorial e social (ZINGONI, 2003).

A participação da sociedade redefine as responsabilidades e funções (tanto da sociedade como do poder público) com a revisão/redistribuição de competências e responsabilidades, comprometendo todos com o perfil de sociedade que se quer. Nessa perspectiva, as decisões não são mais tomadas por alguns que detêm o poder político, mas sim por todos que são afetos às decisões e, portanto, devem ser chamados e desafiados a serem partícipes.

Ressalva-se que, sob o olhar participativo do planejamento coletivo das cidades com a respectiva reorganização dos espaços de prestação de serviços sociais, de cultura, de formação, de lazer e esporte, não se exime a responsabilidade do Executivo em gerir o bem público, mas passa ele a ser articulado através de processos de cogestão e de corresponsabilidades. Alguns dos mecanismos para promover/desenvolver a educação participativa, o senso crítico, o exercício da ética e a responsabilidade social são as 
escolas, pois estas se acredita, têm significativo potencial para a formação humana e o desenvolvimento social.

\section{A Necessidade da Reorganização dos Espaços Públicos Comunitários}

A reorganização dos espaços públicos existentes nas cidades, como uma forma de se tornarem espaços de desenvolvimento da sociedade em diferentes aspectos, é fundamental para que as pessoas possam estar sempre se qualificando, incrementando gosto de estudar, se culturalizando, praticando o convívio social, o lazer e esporte. Para Ferreira (2007), esses locais devem ser considerados como espaços de promoção e cidadania, de educação, dotados de estrutura física qualificada e de equipamentos para contribuir com a educação geral da sociedade, a convivência com espaços culturais e a prática esportiva e de lazer para toda a sociedade.

Não precisamos, necessariamente, construir novos espaços, mas, em um primeiro momento, redimensionar os já existentes no patrimônio municipal, de forma que, em determinados horários, possam ser utilizados pela sociedade em geral para outras finalidades formativas. Para Zingoni (2003), o espaço físico de uma escola poderá ser transformado em centro cultural, local de prática esportiva e de lazer, local de convivência e intercâmbio social esportivo, espaço cultural e artístico, local de ações preventivas de saúde familiar, alimentar, meio ambiente, saneamento básico e de desenvolvimento social, local de realização de diversas oficinas pedagógicas formativas, em diferentes áreas tecnológicas e de formação técnica profissional. Espaços onde as pessoas podem esquecer, pelo menos por alguns instantes, do celular, do tablet e do computador para "se conectar" em atividades sociais, coletivas, prazerosas e que envolvam efetivas ações corporais, principalmente práticas esportivas. 
Para que se possa pensar nessa lógica de ocupação dos espaços públicos, temos o compromisso de criar condições a que toda a sociedade se sinta comprometida com a participação e o envolvimento nos diferentes projetos sociais e formativos. Ao mesmo tempo, devemos construir formas de que a comunidade tenha o compromisso e a responsabilidade social em ajudar a preservar/cuidar o espaço, que passa a ser dela.

Acredita-se na ideia de aproveitamento dos espaços existentes no município, no bairro, nas vilas, como locais comunitários, espaços privilegiados para a potencialização de novas vias de participação comunitária e de desenvolvimento social. Desenvolver sentimentos de pertencimento a um grupo, ter vontade de se envolver e buscar soluções aos seus problemas, bem como os problemas dos outros, são vínculos afetivos que vão se estabelecendo, baseados em ajudas mútuas e gerando solidariedade entre as pessoas e proporcionando uma vida comunitária intensa. Essas são situações que as comunidades antigas faziam muito bem, mas que, com o passar dos tempos, foi-se perdendo esse convívio comunitário, tão importante à humanização do ser humano. Nesse contexto existia mais colaboração, cooperação, ajuda mútua, além da cultura de gostar de ajudar e estar com os outros.

Para que isso aconteça, o Poder Público deve articular ações concretas em suas políticas de governo, condições efetivas de ocupação dos espaços públicos para a educação geral da sociedade, com recursos materiais e equipamentos, recursos humanos e financeiros suficientes e de qualidade, democratizando o acesso, organizando e estimulando a comunidade a sua participação. Também, o centro das decisões passa para o coletivo do centro comunitário:

[...] a administração local não tem de ser a promotora de todas as iniciativas, mas deve ter uma política educativa congruente $\mathrm{e}$ integradora de modo a que os projectos escolhidos respondam a necessidade da população e seu impacto educativo possa ser avaliado na 
definição de suas diferentes políticas para atender as suas verdadeiras necessidades (FERREIRA, 2007, p.2).

O papel do Poder Público passa a ser, além da responsabilidade de articulação das diferentes etapas do processo, o de possibilitar reais condições de participação da sociedade na definição das prioridades e das diferentes ações a serem por ele organizadas. Considera-se importante que essa participação ocorra através do planejamento, controle e execução de projetos, da cogestão de responsabilidades e da parceria entre o setor público e o privado, envolvendo instituições educativas, culturais, desportivas e de lazer, comunitárias, recreativas, sindicatos, partidos políticos, organizações não governamentais (ONGs), movimentos sociais organizados e a sociedade em geral (ZINGONI, 2003).

A proposta de estruturação, organização e gestão dos espaços públicos comunitários deve estar sistematizada, normatizada e regulamentada pelo Conselho Comunitário, representativo das diversas entidades existentes na comunidade e das diferentes manifestações culturais, artísticas, esportivas e de lazer, com poderes instituídos legalmente e constituídos por um colegiado representativo de todos os segmentos e movimentos sociais organizados, de forma que possam definir e organizar suas diversas ações e diferentes interesses. Ao Poder Público compete, além de dotar de todas as condições de infraestrutura e de recursos financeiros, a criação de uma equipe intersetorial do serviço público, aproximando o máximo possível a prestação de serviços básicos à comunidade.

Portanto, pensar uma cidade que possa respeitar seus cidadãos e ser educadora, que contribua com a qualidade de vida das pessoas e o seu desenvolvimento social, é pensar nas estruturas físicas/materiais/humanas existentes, em que verdadeiramente as 
instituições públicas e privadas, as entidades representativas, as diferentes manifestações culturais, artísticas, esportivas e de lazer, os movimentos sociais e o sistema educativo convivam na busca do desenvolvimento social das pessoas. Acreditase que desse modo haverá uma participação efetiva no processo formativo, complementando-se cada segmento com suas especificidades e suas responsabilidades sociais, atuando de forma conjunta, dialogando e buscando formas para contribuir com o processo formativo da sociedade em geral.

\section{Apresentando alguns Caminhos para "Propositar": Algumas Considerações}

A organização dos espaços públicos comunitários é uma alternativa que se propõe a pensar a cidade, seus problemas estruturais e atender às demandas de uma sociedade em constantes transformações. Percebemos os referidos espaços públicos comunitários e educativos como uma possibilidade de intervenção e organização da sociedade para a melhoria da qualidade de vida e do desenvolvimento pessoal e social, da comunidade tendo como prioridade à participação conjunta de todos os envolvidos no processo.

Portanto, pensar esses espaços públicos, sua reorganização e suas possibilidades de vida comunitária, de desenvolvimento de políticas públicas sociais e de esporte e lazer requer a superação de muitos desafios, debates a empreender, pesquisas e estudos a socializar e realizar, para que possamos vislumbrar a construção de uma sociedade mais humana, igualitária, socialmente desenvolvida e justa para com todos.

\section{REFERÊNCIAS}

ARROYO, Miguel. O direito a tempos-espaços de um justo e digno viver. In: MOLL, Jaqueline (Org.). Caminhos da educação integral no Brasil: direito a outros tempos e espaços educativos. Porto Alegre: Penso, 2012. 
BONALUME, Cláudia Regina: Políticas públicas de esporte e lazer em Caxias do Sul: uma vivência construída coletivamente. Participe: revista de participação e cidadania / Associação da participação, Instituto de Políticas públicas da FIDENE : v. 5, n. 8 e 9 (jan./jun. - jul./dez. 2005), 2005.

DIETRICH,K.;LANDAU, G. - Sportpädagogik: grundlagen, positionen, tendenzen. Reinbeck bei. Hamburg: Rororo, 1990.

FERREIRA, A. Gomes. As cidades educadoras. Faculdade de Psicologia e Ciências da Educação, Universidade de Coimbra. Portugal. Mimeo (2007).

GÓMEZ Granell, Carmén; VILA, Ignácio (Coord.) La Ciudade como proyeto Educativo. In: Introducción. Ediciones Octaedro. 2001.

MOLL, Jaqueline (Org.). Caminhos da Educação Integral no Brasil: direito a outros tempos e espaços educativos. Porto Alegre: Penso, 2012. 504 p.

ZINGONI, Patricia. Descentralização e Participação em Gestões Municipais de Esporte e Lazer: In WERNECK Christiane Luce Gomes; ISAYAMA Hélder Ferreira (Orgs.). Lazer, Recreação e Educação Física. Belo Horizonte: Autêntica, 2003.

\section{Endereço do Autor:}

Rosalvo Luis Sawitzki

Av. Roraima, 1000 - Prédio 51 - Camobi

Campus Universitário - KM 9

Santa Maria - RS - 97105-900

Endereço Eletrônico: rosalvols@hotmail.com 